\title{
“Black Mirror" e aprendizagens em rede: distopia, retrotopia e utopias em vivências (trans)formadoras na educação
}

\section{"Black Mirror" and networked learning: dystopia, retrotopia and utopias in (trans)formative experiences in education "Black Mirror" y aprendizajes en red: distopia, retrotopia y utopias en vivencias (trans)formadoras en la educación}

ADRIANA ROCHA BRUNO

JUDILMA ALINE SILVA

Sebastĩ̃o GOMES Almeida JúNIOR ${ }^{c}$

\section{Resumo}

O presente artigo apresenta três experiências de pesquisa desenvolvidas pelo Grupo de Pesquisa Aprendizagem em Rede, fomentadas com episódios da série de TV britânica "Black Mirror - BM". Tendo como objetivo os estudos da cultura e educação digitais, a primeira vivência (trans)formativa se deu no interior do grupo de estudos, seguida de outra que envolveu o grupo e estudantes da Faculdade de Educação e uma última, com jovens que cumprem medidas sócioeducativas em regime semi-aberto. Sob o viés teórico de estudos recentes da cibercultura, destacam-se conceitos tratados por Pierre Lévy $(1999,2014)$ e por André Lemos (2018), em diálogo com conceitos de distopia (JACOBY, 2007), retrotopia (BAUMAN, 2017) e utopia (FREIRE, 2006a). A análise, em meio a pesquisa narrativa (CLANDININ e CONNELLY, 2011), considerou que no mundo atual coexistem movimentos

\footnotetext{
a Universidade Federal do Estado do Rio de Janeiro (UNIRIO), Rio de Janeiro, RJ, Brasil. Doutor em Educação, e-mail: arbruno2208@gmail.com

b Universidade de Federal de Juiz de Fora, Juiz de Fora, MG, Brasil. Doutora em Educação, e-mail: judilma@gmail.com

' Universidade de Federal de Juiz de Fora, Juiz de Fora, MG, Brasil. Doutor em Educação, e-mail: titojnr2@gmail.com
} 
de distopia, retrotopia e utopia e que os episódios da série refletem a função social que as tecnologias digitais assumem na vida contemporânea.

Palavras-chave: Aprendizagem em redes. Educação e "Black Mirror". Vivências (trans)formadoras na educação.

\section{Abstract}

The present article presents three experiences of research developed by the Research Group Learning in Network, nurtured with episodes of the British television series "Black Mirror - BM". Having as objective studies of digital culture and education, the first experience (trans)formation took place within the group of studies, followed by another that involved the group and students from the Faculty of Education and the last one, with young people who meet educational social measures in semi-open. Under the theoretical bias of recent studies of cyberculture, we highlight concepts treated by Pierre Lévy $(1999,2014)$ and by André Lemos (2018), in dialog with concepts of dystopia (Jacoby, 2001), retrotopia (BAUMAN, 2017) and utopia (Freire, 2006a). The analysis, in the midst of the research narrative (CLANDININ \& CONNELLY, 2011), considered that the current world coexists movements of dystopia, retrotopia and utopia and that episodes of the series reflect the social function that digital technologies play in contemporary life.

Keywords: Learning in networks. Education and "Black Mirror". (trans) formative experiences in education.

\section{Resumen}

El presente artículo presenta tres experiencias de investigación desarrolladas por el Grupo de Pesquisa Aprendizagem em Rede, fomentadas a partir de episodios de la serie de televisión británica "Black Mirror - BM". Teniendo como objetivo los estudios de cultura y educación digitales, la primera vivencia (trans)formadora se dio en el interior del grupo de estudios, seguida de otra que se desarrolló el Grupo y estudiantes de la Facultad de Educación y la última, con jóvenes que cumplen medidas socioeducativas en regímenes semi-abiertos. Sobre el sustento teórico de los estudios recientes de cibercultura, se destacan conceptos tratados por Pierre Lévy (, 1999, 2014) y por André Lemos (2018), en diálogo con conceptos de distopia (JACOBY, 2001), retrotraía (BAUMAN, 2017) y utopia (FREIRE, 2006a). El análisis, en medio de la investigación narrativa (CLANDININ e CONNELLY, 2011), consideró que en el mundo actual coexisten movimentos de distopía, retrotopía y utopia y que los episodios de la serie reflejan la función social que las tecnologías digitales asumen en la vida contemporanea.

Palabras clave: Aprendizaje en red. Educación y "Black Mirror". Vivencia (trans)formadora en educación. 


\section{Introdução}

A perspectiva de desencadear um espaço de diálogo no grupo de pesquisa significa, diante dos desafios da educação hoje, propor um ambiente de estudo provocador e produtivo de palavras e contrapalavras, do que os participantes desses encontros enunciam, alargando suas referências. É com esse movimento que o GRUPAR (Grupo de Pesquisa Aprendizagem em Rede) fomenta o diálogo e o contato, os estudos e pesquisa com a cibercultura, com criação tecnológica, audiovisual. Sustentados em Bakhtin (1997), compreendemos que as narrativas são produzidas historicamente e que os eventos humanos são acessados pela arte. Essa perspectiva também nos dá subsídios para pensar a importância da escuta, valorizando o conhecimento que se constrói na tessitura dos enunciados dos sujeitos envolvidos, seja nas formações ou nas atividades propostas pelo grupo de pesquisa. Assim, na interação "eu-outro", no círculo de participantes, de olho na tela, afetados pela linguagem fílmica, se fez o espaço de debate sobre essa realidade retratada em Black Mirror.

Nesta atmosfera, o presente artigo apresenta três experiências de ensino-pesquisa desenvolvidas pelo Grupo de Pesquisa mencionado, gestadas com episódios da série Black Mirror ${ }^{1}$, ocorridas entre agosto de 2017 e junho de 2018, com foco nas tecnologias digitais e as implicações decorrentes das relações estabelecidas no contexto da cibercultura.

Tendo como foco das pesquisas do grupo, os estudos e discussões envolvendo tecnologias digitais e em rede e seus desdobramentos para os processos (trans)formativos na cultura e na educação, promoveu-se experiências fílmicas disparadas com episódios da referida série. A primeira experiência de (trans)formação ocorreu no segundo semestre de 2017 e mais outras duas se deram no primeiro semestre de 2018. Tais proposições foram compostas na dinâmica de debates que são uma das marcas dos encontros quinzenais para estudos ${ }^{2}$ do referido grupo de pesquisa.

\footnotetext{
1 Série televisiva britânica de ficção-científica criada por Charlie Brooker, inicialmente difundida entre 2011 e 2014, e que alcançou estrondoso sucesso mundial. A partir de 2016 suas temporadas passaram a ser produzidas pela Netflix. Seus episódios são marcados por apresentar um futuro próximo distópico no contexto das tecnologias digitais e as mídias sociais.

2 Nos encontros do grupo de pesquisa são previstos estudos planejados pelos seus integrantes. Além da leitura de textos de autores de referência para o grupo, outras atividades são integradas
} 
Os primeiros fios dessa tessitura começaram a tomar forma a partir de uma das reflexões sobre as mídias sociais e o ambiente tecnológico de nosso tempo, num dos encontros de planejamento do GRUPAR, no primeiro semestre de 2017. Para além de ser a opção de debater uma série de ficção científica e distopia que aborda, com qualidade de roteiro e atuações, diversos dramas e situações que são ambientadas no universo das tecnologias digitais de informação e comunicação, a decisão se deu pela sua potência de referências da cibercultura muito próximas da realidade vivida, nas questões éticas, comportamentais e humanas que a série revela. Em Black Mirror é possível vislumbrar uma miríade de espectros em seus episódios em que as tecnologias assumem um papel decisivo estarrecedor, que nos afeta de modo singular. Ao problematizar a realidade do presente em que as pessoas têm seu palanque amplificado pelas tecnologias e pelas redes sociais, de acesso fácil aos softwares de comunicação, diversas questões emergiram no grupo de pesquisa: estaríamos ou não nos aproximando dos modos de vidas sombrios e apocalípticos apresentados pelos episódios da série Black Mirror? O quanto esse futuro distópico apresentado por Black Mirror espelha a realidade de nosso tempo? Estaríamos cada vez mais ameaçados por uma exacerbação da presença das mídias sociais no nosso convívio? Ou esse quadro sombrio e apocalíptico seria uma fantasia futurista que reflete algo inimaginável num futuro próximo? Estas e outras perguntas já se colocavam, antecipadamente, instigando uma discussão mais aprofundada no Grupar.

Além disso, tais questões, longe de terem respostas únicas, são convites às multiplicidades do pensar e do perceber-se no mundo, e diante delas, sobre a presença das tecnologias nas nossas vidas, com suas seduções, temores e projeções, se tornou pertinente refletir e aprofundar o debate sobre o quanto a presença das tecnologias em rede nos afeta, tendo como referência situações exploradas pelos episódios da série. Acreditamos que os elementos disparadores dos episódios são iscas pertinentes para favorecer o debate e instigar a curiosidade para relacionar com os temas estudados no grupo.

Dando curso à proposta de estudo, no segundo semestre de 2017, no interior dos encontros quinzenais do GRUPAR, seus integrantes selecionaram quatro episódios da

no incremento das discussões promovidas nesses encontros, como rodas de conversa com a presença de pesquisadores, oficinas e filmes com debate. 
série, situados entre a primeira e terceira temporadas ${ }^{3}$ : Nosedive (“Queda Livre” — Temporada 3, ep. 1); The Entire History of You ("Toda sua História” - Temporada 1, ep. 3) 4; White Bear ("Urso Branco" - Temporada 2, ep. 2); e Shut Up and Dance ("Manda Quem Pode" - Temporada 3, ep. 3).

Entre março e junho de 2018, outras duas experiências ocorreram tendo como mote de debates e reflexões episódios da série Black Mirror: a primeira delas envolveu pesquisadores do Grupar e estudantes da Faculdade de Educação-FACED (graduação e pós-graduação), num evento denominado "Seminário de acolhimento aos estudantes na FACED" e que contou com 23 estudantes (dos cursos de pedagogia, história, geografia e matemática) em intenso debate sobre os processos formativos hodiernos, provocados pelo episódio Nosedive ("Queda Livre” — Temporada 3, ep. 1); a segunda experiência teve como disparador um convite ao Grupar para discutir os temas Bulliyng e Ciberbullying em uma $\mathrm{ONG}^{5}$, conveniada ao Governo do Estado de Minas Gerais, junto a dezessete menores em situação de semiliberdade. Tendo o grupo de pesquisa a oportunidade de desenvolvimento da temática junto aos jovens, que convivem em situação de risco social e violência. O episódio Shut Up and Dance ("Manda quem pode" — Temporada 3, ep. 3) foi escolhido para proporcionar o debate.

Assim, nesse artigo trazemos um recorte das discussões dos episódios: Nosedive — debatido no interior das discussões do grupo de pesquisa e também no evento da FACED, White Bear - debatido no interior das discussões do grupo de pesquisa, e Shut Up and Dance — debatido por dois integrantes do grupo junto a um grupo adolescentes em situação de semiliberdade, que cumprem medida socioeducativa.

Para fundamentar as discussões, optamos por referenciais teóricos que pudessem dar conta de abordar as questões decorrentes do exercício proposto de fruição de obra audiovisual seguido de debate. Dessa forma, para dar corpo e densidade à formação, nos fundamentamos em teóricos da cibercultura, educação e sociedade, circunscritas ao tema de estudo.

\footnotetext{
${ }^{3}$ No início dos trabalhos a $4^{\text {a }}$ temporada da série ainda não estava disponível para os assinantes.

${ }^{4}$ Esse episódio, inicialmente previsto para o debate, não foi discutido presencialmente no grupo. Entretanto, fez parte do planejamento como sugestão de atividade individual para acessar o conteúdo da série.

5 Por razões éticas não identificaremos o nome da entidade.
} 
Subsidiando algumas das reflexões propostas sobre os episódios que integraram as questões exploradas pelo grupo nos encontros, foram relevantes alguns apontamentos do livro de Pierre Lévy, “A esfera semântica” (2014), com especial atenção aos conceitos de Personal Knowledge Managment - PKM (Gestão pessoal dos conhecimentos), a obra de André Lemos (2018) intitulada "Isso (não) é muito Black Mirror" que trata especificamente da série, analisando cada um de seus episódios, em diálogo com os conceitos de distopia (JACOBY, 2007), retrotopia (BAUMAN, 2017) e utopia (FREIRE, 2006a), necessários para um debate profícuo escoado dos episódios da série Black Mirror.

Além disso, as discussões intensas ocorridas no grupo potencializaram aprendizagens e links com outros autores que versam sobre a realidade cultural do presente: Guy Debord (2003) e a "Sociedade do Espetáculo", e considerações de Yves de La Taille (2016) sobre a moral e ética no mundo contemporâneo.

As experiências foram analisadas a partir de referenciais da pesquisa narrativa e/ou com as narrativas fundamentadas por Clandinin e Connelly (2011) e também por Bakhtin (1997) e as narrativas associadas às cadeias de enunciados. Vale destacar que o método narrativo converge com os estudos desenvolvidos pelo Grupar, especialmente no que tangem à Educação Aberta, a multirreferencialidade e transdisciplinaridade, alicerces para as pesquisas do grupo, mas que não serão diretamente tratados neste artigo.

\section{Vivência 1: futuro distópico na tela — episódios de “Black mirror" em debate no grupar}

Vivemos num mundo de explosão de imagens, de muitas telas e de fluxos de informações que conectam as pessoas. Nessa realidade da sociedade e da cultura midiatizada do presente, de produção e consumo, de exposição dos indivíduos e da suas implicações e seus efeitos, o debate sobre as tecnologias na atualidade é fundamental. A série de ficção científica da televisão britânica Black Mirror, que apresenta um quadro apocalíptico sobre esse ambiente sociotécnico tendo um papel preponderante num futuro próximo, ambientado num cenário futurista de controle e de opressão, nos provoca a pensar o quanto estaríamos muito próximos de situações vividas pelas 
personagens. Ainda que os tons carregados em um fictício e aterrorizante futuro distópico sejam o plot da série, o debate sobre as tecnologias digitais na contemporaneidade e da cibercultura já fomenta muitas reflexões sobre o papel das tecnologias na atualidade. Para os integrantes do GRUPAR, pesquisadores e educadores em constante movimento de pensar a educação nessa interface, a série se tornou um disparador no sentido de potencializar problematizações mais profundas sobre os temas desse contexto.

As discussões do grupo, num determinado momento, se debruçaram em meio a obra de Lévy (2014), com especial atenção aos conceitos de Personal Knowledge Managment - PKM (Gestão pessoal dos conhecimentos) e a conversação criativa. Os fluxos de conhecimento criativo emergem das relações entre os ecossistemas representados pelas comunidades e a consequente potencialização de aprendizagens individuais nesse ambiente. As redes de informação discutidas pelo autor ressaltam que a potencialidade de informações compartilhadas no ecossistema de saberes ampliaria o leque de compreensões, alargando as visões sobre aquilo que está em destaque exposto nas mídias. As redes de conhecimento, portanto, possibilitam outras leituras e percepções sobre a vida, o outro, os acontecimentos e os artefatos culturais.

Quando apresentamos na pesquisa relatos/vivência nos diversos espaços formativos é para compartilhar um aprendizado que é ao mesmo tempo a apropriação e a produção de um saber e a investigação deste saber. Nesta direção, pensamento de Gallo (2008, p. 29), que faz referência a Deleuze como "filósofo das multiplicidades", infere acerca da teoria das multiplicidades, e nos ajuda a compreender o campo de produção de ideias como plano de imanência, um espaço infinito em que não há afirmações como verdades e achados definitivos. A respeito do plano de imanência, Gallo (2008, p. 44) revela que "é essencialmente um campo onde se produzem, circulam e se entrechocam os conceitos."

O pesquisador-professor está, nesse sentido, em constante trabalho com os devires, ou seja, está dentro do campo e faz parte do lócus no qual está investigando e produz, junto aos sujeitos e o próprio campo, os dados emergentes das observações e entrevistas. O devir para Deleuze e Guattari (1997, p. 14) "não é uma correspondência de relações. Mas tampouco é ele uma semelhança, uma imitação e, em última instância, uma identificação", mas trata-se de uma outra forma de viver, de sentir, de ser. 
No ambiente comunicacional contemporâneo é possível constatar a variedade de ofertas de imagens que abundam, onde o espaço público e o ambiente privado possuem tênues fronteiras de separação. Nas conexões existentes pelas diversas redes, a exposição das pessoas ganha cada vez mais notoriedade, estimulando a exibição, a curiosidade em torno de aspectos particulares. A ubiquidade, a comunicação fluida e de largo alcance se torna o grande veículo de promoção de si e do consumo do outro. Essa discussão sempre muito presente nos debates do Grupar ensejou a escolha do primeiro episódio para o debate a partir de Black Mirror.

\section{A vida alimentada pelos likes: o culto e exposição de si amplificado pelas as redes}

Como é viver em um mundo em que as imagens produzidas de si e a pontuação de likes conduzem nossas vidas? O episódio Nosedive ("Queda Livre”), dirigido por Joe Wright, que faz parte da $3^{a}$ temporada da série expõe um mundo de um futuro próximo — e muito familiar — em que as pessoas são avaliadas em sua popularidade por estrelas que geram pontuações numéricas com apenas um click no aparelho celular. Não somente as relações pessoais são pontuadas, mas todo tipo de relação cotidiana: profissional, de estudo, prestação de serviços, aquisição de bens e serviços, etc. (LEMOS, 2018). O bemestar, o status social e a felicidade ideal obtida por likes, perseguidos obsessivamente pela personagem Lacie Pound, conduz a trama da narrativa que explora consequências imprevistas e desastrosas em uma sociedade em que as pessoas são moldadas e rankeadas pelas tecnologias, a serviço de uma sociedade que controla tudo em acordo com padrões preestabelecidos e que devem corresponder ao desejado/esperado de todo/a cidadão ou cidadã.

Esse episódio foi o tema que abriu as temporadas de discussão de Black Mirror na roda de discussões do grupo de pesquisa. Como as mídias sociais vêm fomentando a exposição da privacidade das pessoas na atualidade? Vivemos processos de artificialização e de uma superficialidade mediadas pelas redes sociais ou as redes seriam espaços de manifestação, de expressão e de perspectivas pessoais sobre a realidade? 
Essas provocações, que circularam no grupo antes, durante e depois de assistirmos/debatermos este episódio, integraram conversas compostas por vários exemplos vivenciados no Facebook e no Whats App pelo grupo.

Alguns pontos debatidos são destacados: 1. há ocorrência de um recrudescimento dessa cultura que expõe as pessoas e as estimula a conviverem com a valorização da popularidade e do consumo nas mídias sociais; 2 . desligadas de cada um dos aspectos da vida, as imagens fluem e vão formando um pseudo mundo para ser objeto de contemplação; 3. tal como um looping, as enxurradas de informações, assuntos, acontecimentos e demandas nas redes, sobrecarregam o cotidiano das pessoas, levandoas a agir mecanicamente, sem acionar muitos filtros, se deixando levar por processos de condicionamento que limitam (às vezes impedem) ações críticas, e/ou ponderadas.

Tais aspectos foram linkados com a obra de Lévy (2014), "A esfera semântica”, em estudo pelo Grupar, com ênfase à Conversação Criativa e a Gestão Pessoal de Conhecimentos (Personal Knowledge Managment — PKM). Em acordo com o autor, hoje, a participação em mais de uma comunidade cultural suscita uma intensa gestão do conhecimento, como um "processo autopoiético de construção, reprodução e transformação de ecossistemas de saberes" (p. 143) e isso envolve um esforço pessoal da aprendizagem. Esta gestão implica em gerir a atenção de modo a integrar concentração e abertura/seletividade, ou seja, a escolha das fontes - quem nos alimenta, nos "alfineta", nos instiga, é o que nos faz sair do lugar e, portanto, a necessidade de dar destaque à seleção de pessoas, quem vamos "seguir". O conhecimento, portanto, é hoje também construído por meio de sínteses críticas e criativas fomentadas em meio a conversação, registros públicos e periódicos, exposições a críticas e comentários, e, assim, o uso de tags são priorizados.

Num primeiro momento, o mundo "Nosedive" pode nos levar à ideia de que vivemos numa "bolha social", como tem sido amplamente tratadas as redes sociais, divulgando a ideia de que somos controlados pelas redes, suas marcas, suas operações, suas culturas. Mas não podemos esquecer a influência que a denominada web semântica traz para este tipo de concepção, pois os algoritmos incorporam nossos trajetos e preferências pelas redes, favorecendo determinados padrões. Este episódio, que mexeu de modo singular com cada um dos membros do grupo, fez com que mais e mais questões brotassem naquele cenário de inquietação: Que valores são esses em que 
medimos o outro pelo que ele usa e pela sua aparência? O que têm sido os likes em nosso tempo?

$\mathrm{Na}$ sociedade do espetáculo, a relação social é mediatizada pelas imagens: "toda vida nas sociedades nas quais reinam as condições modernas de produção se anuncia como uma intensa acumulação de espetáculos” (DEBORD, 2003, p. 13).

Refletindo o que denomina "cultura da vaidade", o psicólogo Ives de La Taille (2016) ressalta os indícios desse fenômeno da exposição das pessoas na atualidade. Destaca, além da exacerbação da sociedade do espetáculo, o recrudescimento do culto da celebridade nas mais diferentes formas de exposição, e neste ponto evidencia-se o lugar de distinção para o quantitativo de likes nos diversos espaços das redes sociais digitais. O vencedor, objeto de veneração, é outro indício dessa cultura que valoriza líderes com a característica do sucesso na vida social, opondo-se ao temível estigma de perdedor; e no caso do episódio, as perdas são enormes, pois capilarizam-se por todas as áreas da vida humana. Acrescentam-se o consumo, onde o valor daquilo que se possui assegura a promoção pessoal, aqui exacerbada, mas não alterada, pelo cenário tratado no episódio de Black Mirror, e por fim, a violência, já que esta se afirma nesse contexto, em que a invisibilidade é vista com algo negativo, e assim, os atos violentos ganham visibilidade para aquele que pratica o ato. Este aspecto ganha ainda mais espaço e força em meio às mudanças sociais mundiais, de caráter mais conservador, que ganha as redes para se tonificar e disseminar pensamentos e práticas segregatórias, discriminatórias. Neste cenário, e confirmando o foco do episódio, somente os outsiders podem resistir, pois se desvinculam dessa cultura do controle e do consumo, conquistando a liberdade. As consequências, no entanto, não são fáceis.

Ratificando tais premissas, Lemos (2018) nos alerta que “a questão central desse episódio é o monitoramento das relações sociais, as métricas e estratégias para conseguir pontos aumentando a reputação social e a vigilância distribuída pela possibilidade de julgar e punir o outro com pontos" (LEMOS, 2018, p. 84).

Retomando o conjunto de indícios dessa cultura em que impera o espetáculo de si, podemos resgatar das discussões levantadas pelos participantes do encontro de discussão sobre "Nosedive" (Queda Livre) o quanto somos bombardeados por estímulos nas mídias sociais, personificada por tantos estímulos ao culto da vaidade, do sucesso e 
do consumo, e o quanto a violência também pode estar personificada nas provocações desse ambiente que aproxima as pessoas, mas também pode ser geradora de conflitos.

Ao tratar do universo da Cibercultura, Lévy (1999) já pontuava que a sociedade está vivendo um momento no qual a rede opera relações e situações de comunicação entre pessoas próximas ou distantes umas das outras. Este é o ciberespaço. Construído com a atuação dos usuários, esse ecossistema se constitui em meio a transformações técnicas da vida hodierna, promovendo mutações sociais e culturais. "As tecnologias digitais surgiram, então, como a infra-estrutura do ciberespaço, novo espaço de comunicação, de sociabilidade, de organização e de transação, mas também novo mercado da informação e do conhecimento" (LÉVY, 1999, p. 32). Nessa perspectiva, podemos refletir o quanto a cibercultura se consolida na contemporaneidade e como ela tem impactado a vida humana, a sociedade e suas instituições, repercutindo em novas formas de ser e estar no mundo pela mediação tecnológica.

Já Castells, em sua obra "Sociedade em rede" (2007), define as tendências da sociedade atual com o advento da era da informação. Para o autor, essas redes nas quais a sociedade está influenciam os processos produtivos, as experiências, o poder e a cultura. De acordo com Castells (2007, p.566) "uma estrutura social com base em redes é um sistema aberto altamente dinâmico suscetível de inovação sem ameaças ao seu equilíbrio".

Dessas considerações, podemos refletir o quanto as redes sociotécnicas da atualidade estão diretamente ligadas a toda uma cultura que se reconfigura onde ocorrem modulações influenciadas pela convivência humana nesse ambiente. A exacerbação do domínio das mídias sociais, especificamente sobre esse episódio de Black Mirror nos faz pensar no quanto os comportamentos que são alimentados pela participação dos seus usuários não estaria reforçando uma cultura da superficialidade e das representações de si. Ao fazermos escolhas de nossos conteúdos e imagens em função dos likes, temendo a exclusão da vida social, a rede que se cria nessa retroalimentação estaria nos intimidando a assumir um papel cada vez mais afirmativo assumindo uma representação artificializada de nós mesmos para outro. Nosedive ("Queda Livre") questiona e leva às últimas consequências o quanto nos afastamos de nossa essência humana e caimos na armadilha de moldar representações de nós mesmos para povoar um mundo idealizado e asséptico, sem as contradições, diferenças e imperfeições inerentes à existência. 


\section{A exacerbação do espetáculo midiático e a ética: "justiceiros" em rede}

O espetáculo midiático ao extremo é explorado pelo episódio White Bear ("Urso Branco"), e foi o segundo discutido no grupo de pesquisa. A personagem Victoria acorda em um quarto. Sem se lembrar de nada, a jovem observa a vizinhança da casa onde está, e vê pessoas à sua volta gravando imagens dela em celulares. Além disso, imagens com uma criança, supostamente sua filha, a cercam.. Sem conseguir que as pessoas que estão a registrar as suas imagens a ajudem, ela vive o terror ameaçador de ser perseguida por um agressor com máscara de animal que a persegue com arma de fogo para assassiná-la. $\mathrm{Na}$ tentativa enlouquecida de fuga, a personagem consegue ajuda de dois jovens, e sua sobrevivência se restringe à invadirem a central de transmissão de imagens, White Bear, que seria a suposta causa da alienação mórbida dos habitantes do local, que se comportam de forma hipnótica empunhando seus celulares como zumbis, registrando o desespero da jovem.

No debate que se seguiu à exibição do episódio, a presença da mídia, a ação dos indivíduos e a ética na atualidade foram centrais. O quanto no mundo de hoje estamos sendo bombardeados por tantas notícias, imagens de tragédias e fatos que ferem a moral, e sobre os quais nos posicionamos. Tanto nos meios massivos e amplificado pelas redes, que vêm cada vez assumindo um espaço público de difusão de informações sobre violência de diversas naturezas, nos mobilizando a assumirmos um posicionamento. Como em White Bear, corremos o risco de atuarmos como os algozes da execução das sentenças coletivamente, arrebanhados pelos meios de comunicação.

Se há certo consenso de que a série Black Mirror é distópica, precisamos adentrar ao significado do termo e seus desdobramentos. Utopia significa não lugar: u — negação, topos — lugar. Já distopia significa lugar ruim, mau: dis — mau/ruim e topia — lugar. Entretanto, o sentido dado à distopia tem sido de contrário à utopia. Jacoby (2007) pontua que a palavra distopia (que é também abordada por ele como antiutopia) surgiu no século XX e não tem sentido de contrário, inverso à utopia, pois o prefixo dis não carrega este significado. Para este autor, “as distopias são habitualmente vistas não como 
o oposto das utopias, mas como o seu complemento lógico" (JACOBY, 2007, p. 33). Nesta direção, considerando as ideias do autor, a série poderia ser compreendida como utópica E distópica: “as utopias buscam a emancipação ao visualizar um mundo baseado em idéias novas, negligenciadas ou rejeitadas; as distopias buscam o assombro, ao acentuar tendências contemporâneas que ameaçam a liberdade" (p. 39-40). Porém, há prevalência na série de uma visão mais pessimista das sociedades e das tecnologias digitais em si nas culturas, e daí a aproximação com a distopia.

A ficção científica tem a capacidade de promover um deslocamento do futuro para "camuflar", disfarçar, discussões sobre o mundo presente e, em certa medida é o que ocorre também na série, ainda que em diversos episódios a temporalidade seja incerta, como afirma Couto:

Importa reconhecer o papel de gêneros como a ficção científica, as distopias e a fantasia como gatilhos para a crítica social. Ou seja, suas tramas enganam ao sinalizar criticamente para um futuro distante do que se desejaria para aquela sociedade. O gatilho que mencionei se assemelha a um jogo de espelhos: tais gêneros não falam de um futuro, mas do presente, só que "fantasiado" - fabulado - de futuro (COUTO, 2018, n.p.).

Tal movimento "distópico-utópico" nos convida a pensar no que Bauman denominou retrotopia, como uma volta ao passado proporcionada pelo medo do futuro:

Uma crescente maioria de pessoas já aprendeu, a essa altura, pela própria experiência e pela dos que lhe são próximos e caros, a desacreditar de um futuro desigual, instável, imprevisível e notoriamente decepcionante, como o lugar para investir esperanças [...] Na ausência de ferramentas efetivas de ação capazes de enfrentar os problemas de nossa presente situação, e dado o crescente desapontamento trazidos por sucessivos futuros creditados com o desenvolvimento dessas ferramentas de ação, não surpreende que a proposta de exploração do giro de $180^{\circ}$ pareça ilusoriamente atrativa (BAUMAN, 2017, n.p.).

Este autor destaca que há semelhança entre a utopia e a retrotopia no que tange ao desconhecido, ao não visitado. Passado e futuro não nos pertencem (mais ou ainda). Entretanto, a utopia sempre nos ofereceu esperança, credibilidade. O pensamento utópico sempre nos ofereceu perspectivas de mudanças, e preferencialmente para melhor.

Paulo Freire (2006a, 2006b) traz suas ideias de utopia associadas a conceitos que são basilares em sua teoria: inacabamento, conscientização, esperança, num continuum do se fazer viver em processo dialético, impermanente. O futuro para ele nunca é uma repetição do presente e é por meio da consciência de nosso inacabamento, da 
incompletude que projetamos, que produzimos o futuro. É a esperança a chave para a libertação, para emancipação e para transformação do mundo. Por meio de uma educação libertadora, e portanto utópica, transformamos a nós e o mundo. Esperança e utopia se fundem, se mesclam, se interpenetram dentro do futuro possível, que precisa ser criticamente elaborado para ser praticado, construído.

Sob a perspectiva psicológica de Yves de La Taille (2016), a moral e a ética no mundo contemporâneo assumem novas configurações em uma realidade em que explode a violência, constantemente noticiada pela mídia que condena os atos, notadamente envolvendo jovens em chacinas, situações trágicas e traumáticas para sociedade, muitas vezes praticado por um único indivíduo. Para o autor uma apropriação discursiva da palavra "ética" em sinonímia ou detrimento da moral, que é um princípio humano vinculado a regras, fundamental à vida humana. A ética, distinta da moral, a engloba pois "um indivíduo somente agirá conforme princípios e regras morais (seja quais forem) se essas fizerem, para ele, sentido no plano ético" (LA TAILLE, 2016, p. 33) ${ }^{6}$. Nesse sentido, nos atos praticados, a ética toma corpo segundo um sistema de valores construídos pelas pessoas, sobrepondose ao senso moral, universalmente presente da formação humana. Em sua abordagem, o autor questiona o quanto os valores identitários assumidos na contemporaneidade favorecem a constituição de personalidades éticas.

A horripilante narrativa desse episódio, num eletrizante thriller de terror midiático, expõe um quadro macabro de uma realidade ficcionada onde as tecnologias assumem um protagonismo como condutor dos comportamentos e decisão de vida ou morte sobre as pessoas. White Bear (“Urso Branco”) traz o debate da mídia e da ética levada às últimas consequências, em que o espectador participa de execuções públicas das pessoas.

As duas narrativas tratadas nesta vivência 1 incitam-nos a pensar que utopia, distopia e retrotopia, como pensamento e ato contemporâneos, encontram brechas para coexistirem.

${ }^{6}$ Grifo do autor. 


\section{Vivência formativa 2 - integrando olhares e palavras em "queda livre" na faculdade de educação}

A segunda vivência abordada neste artigo traz uma experiência ocorrida na Faculdade de Educação (FACED) da Universidade Federal de Juiz de Fora), que realizou no início do período letivo uma atividade programada para os estudantes voltada para seu acolhimento e integração ${ }^{7}$. O Grupar, como grupo de pesquisa que integra as ações deste espaço formativo, contribuiu com essa iniciativa oferecendo oficinas e atividades formativas para os estudantes de Pedagogia e dos cursos de licenciatura para os quais são oferecidos um cardápio variado. Além da presença dos participantes matriculados nas disciplinas da FACED, o evento foi aberto para todos os alunos da Universidade com a oferta, concomitante, de palestras, cursos, oficinas, dentre outras atividades formativas. Uma das propostas de formação sob responsabilidade do nosso grupo foi uma roda de conversa a partir do episódio Nosedive ("Queda Livre”), da $3^{a}$ temporada da série Black Mirror, que já havia sido explorada num dos encontros do grupo de pesquisa para debate, tratado anteriormente.

A roda de conversa aconteceu na manhã do dia 18/04/2018 e estiveram presentes 24 estudantes, sendo: 17 do curso de Pedagogia, 2 do curso de História, 3 do curso de Geografia e 1 do curso de Matemática, e ainda uma professora da Faculdade de Educação. Após assistir ao episódio, foram apresentadas algumas questões abertas de modo a promover o debate. Foi avisado (e solicitada autorização) aos participantes que esta atividade seria gravada porque incluía em seus objetivos produzir textos sobre esta vivência no contexto da cibercultura.

A opção pela pesquisa com narrativas emerge por meio de movimentos que vão desde questões disparadoras/mediadoras, até a sustentação do silêncio como lacunas necessárias para a produção de sentidos, ideias e sentimentos. Clandinin e Connelly (2011) explicam a pesquisa narrativa como um modo de compreender a experiência, sendo esta última percebida em meio a uma relação tridimensional: dimensão temporal,

\footnotetext{
${ }^{7}$ Com o objetivo de acolher e integrar os estudantes que ingressam no curso de Pedagogia, nas demais licenciaturas e no Programa de Pós-graduação em Educação (PPGE) da UFJF, a Faculdade de Educação (FACED) realizou a "I Semana de Acolhimento e Integração da FACED". O evento ocorreu entre os dias 17 e 19 de abril de 2018.
} 
que integra o presente, o passado e o futuro; dimensão relacional, que agrega o pessoal e o social); e a dimensão situacional que compõe o lugar ou a sequência de lugares da experiência. Nesta segunda vivência trazemos algumas narrativas dos participantes desta experiência, e tecemos nossa narrativa em meio a tais falas.

As provocações iniciais versaram desde as questões mais básicas, para criar o clima da conversa sobre os sentidos, sentimentos e identificações, até as mais complexas experienciadas em 2017 pelo grupo de pesquisa: O que tem sido os likes em nosso tempo? Até onde a primazia do "ser aceito" nas redes supera a originalidade? Qual o sentido de autenticidade nas postagens que são disseminadas nas redes sociais? Mas, privilegiou-se o movimento do próprio grupo presente, de modo a cocriar um clima singular, próprio daquele momento, daquelas pessoas.

Um dos participantes iniciou dizendo que quando assistiu pela primeira vez, queria ter um debate para conversar e quando viu na programação esta roda de conversa na "I Semana de Acolhimento e Integração da FACED" se interessou, pois Nosedive é um episódio que traz uma crítica acerca do que vivenciamos no privado, e que não é demonstrado. Participante A: "Sempre vivi para mim mesmo. Me parece meio egoísta. As pessoas que eu vou me dar bem vão andar do meu lado e vão gostar de mim, as pessoas que não são para eu me dar bem não vai ser. A vida não é um bicho de 7 cabeças. A vida é assim... você vai andar em rodas e círculos e há pessoas que pensam como você e outras não. Quando a nota da personagem principal vai diminuindo, achei interessante, ela vai realmente tornando outra pessoa. Ela começa a virar um bicho. Pouco se importa se o que está acontecendo é uma crítica social sobre o uso da tecnologia e o ser humano, e a dependência do ser humano em cima do outro. O simples fato de alguém curtir sua foto no Face ou no instagram você fica empolgado. O simples fato de você pensar quem vai gostar, quem não vai gostar da foto, antes de você postar... Quem você vai atingir e não está postando coisas que te agradam”.

Esta narrativa possibilita que compreender o que Lévy (2014) resgata sobre folksonomia, termo que foi cunhado por Thomas Vander Wal em 2004, o qual compreende uma taxonomia indexada ao linguajar mais solto e livre das pessoas nas redes sociais. Lévy fala sobre as tags de folksonomias que são diversas e relacionam múltiplos sentidos e, ainda que caóticas (pois são atribuídas a significados diversos), elas prefiguram a conversação do futuro como é retratado no episódio.

Logo em seguida, uma das mediadoras comenta sobre os estudos no grupo de pesquisa que participa e lança uma pergunta: "Até onde a busca por ser aceito socialmente pode 
mudar e transformar a identidade do ser humano"? A tecnologia pode enganar, mudar ou mesmo levar pessoas a se relacionarem por interesse em troca de uma aceitação?

Participante B: A tecnologia está presente no fato dos aplicativos que são usados, como por exemplo o Uber (Estrelas, acho que não tem que dar estrelas, pois a pessoa está trabalhando) que você tem de dar a nota para o motorista e ele também dá uma nota para o passageiro.

A mediadora "J" pergunta se quando eles usam algum aplicativo tem o hábito de dar notas.

Participante B: Nunca avalio.

Participante C: não fico atento para isso.

Participante D: sempre dou 5, porque a pessoa está trabalhando. A nota não faz a diferença para mim.

Participante E: O motorista tem que me levar de um ponto a outro e está bom.

Participante F: O episódio me incomodou muito, pois já estamos vivendo isso. Penso logo em questão de empresa, pois há empresas que analisam seu perfil em redes sociais. A medida que os dados vão ganhando espaço, o ser humano vai perdendo espaço.

$\mathrm{O}$ ato da avaliação está presente em nosso cotidiano e percebemos que certos aplicativos contribuem, reforçam e intensificam tal prática. Para Álvaro Méndez (2002, p. 14), "no âmbito educativo, a avaliação deve ser entendida como atividade crítica de aprendizagem, porque se assume que a avaliação é aprendizagem no sentido de que por meio dela adquirimos conhecimento". Vinculando este conceito para os aplicativos há de se questionar o que se aprende quando avaliamos com 5 ou 3 estrelas? O que de fato se pretende? O episódio denuncia o que é vivenciado, debatido e intensamente criticado ao longo dos tempos no campo da educação: o ranqueamento, a meritocracia, as disputas.

Álvaro Méndez (2002, p. 20), apesar de apontar que ainda são poucas as obras que questionam a natureza, o sentido e a existência da avaliação, critica a "forma" como se apresenta: instrumento de controle, exercício de autoridade, ou como meio educativo de aprendizagem. Somado a todos estes aspectos, alerta para o lugar de influência do contexto sociocultural em que o ato da avaliação ocorre. Estes elementos são centrais na prática dos likes como mecanismos regulatórios, de controle, que criam sensações de aceitação ou não nos grupos sociais. 
Para elucidar ainda mais sobre esta questão envolvendo a avaliação/aceitação/rótulos/padrões sociais, uma professora que estava presente na roda de conversa, comenta:

Participante X: A todo momento somos avaliados, por nossos pais, família, professor e amigo, que são os expert para tal função. Nas redes sociais estamos sendo avaliados porpessoas que não possuem o menor crédito para tal. Às vezes somos "detonados" por pessoas que não sabem nada da nossa vida. A mudança da avaliação é que incomoda: é o mesmo caso do motorista do aplicativo.

Dando continuidade à conversa, a mediadora "J" pergunta: Até onde está a autenticidade das pessoas?

Participante D: Quando assisti o episódio pela $1^{a}$ vez fiquei muito angustiada e o vi como ele influencia na realidade. A tecnologia nos molda para caber na sociedade. Eu não tinha instagram e tive de fazer de tanta pressão das colegas. Tem 4 meses. Comecei a perceber as pessoas que estão em alta com 15.000/ 30.000 seguidores. Percebi o padrão das pessoas: brancas e em trajes de festas. Para estar "bombando" preciso caber neste padrão, foi o que percebi também no episódio.

Participante C: Às vezes esquecemos-nos do nosso interior, do nosso ser para caber em certos moldes.

Participante G: Sou estudante de História e a parte que coloco é a da experiência do ser bumano que o move e perpassa muito na questão da identidade. Cada ser humano tem sua experiência que gera sua identidade. O desenvolvimento da identidade ocorre através da interação que mantém com o meio em que vive. A construção da identidade apresenta características diversas em razão das diferenças culturais. Com as midias sociais você tem a desvalorização da experiência real.

Ainda que não seja nosso foco entrar aqui nos sentidos de "experiência real", a compreensão de que as vivências nas redes sociais digitais estão apartadas das ocorrências na presencialidade física assume ainda lugar de destaque. A alusão entre presente e futuro trazido por Couto (2018) ao abordar um dos pontos chave da ficção científica ganha espaço notório também neste caso, pois as redes também são integradas na "falsa" ideia de espaços de "distopias" e, em muitos casos, de irreal.

A cibercultura que é sabidamente híbrida e cíbrida mais uma vez se mostra como a cultura do E e do Co: há tensão quando se quer cindir, romper, polarizar, pois é a cultura do pertencimento e das possibilidades e das ambiguidades e do co-laborar e do coexistir e... e... e. 
A Mediadora "M" indaga: Você tem sua vida e sua identidade, mas não muda sua essência. E a partir do momento que você começa a usar as redes sociais você muda para ser aceito.

Prof "X": Mas já não fazemos isto a vida inteira com ou sem a tecnologia? O que mais importa para o ser bumano é ser aceito. As tecnologias potencializam e de certa forma reforçam o que já fazemos.

Participante A: Com a tecnologia "fica na cara" o que estamos fazendo.

Participante G: Sem a tecnologia era mais limitado, pois ficava no bairro e no seu círculo familiar e de amizades.

Participante F: Pagamos um preço por ser autêntico, um preço muito alto. Meus pais tem um grande mérito por me ensinarem a ser o que sou. Eu seria uma 0,2 pelo que falo. Quando vi a personagem na fila do aeroporto, lembrei de mim na fila do supermercado brigando. As pessoas fazendo as coisas erradas. Falar o que pensa incomoda. Há pessoas que utilizam muito o facebook e eu não fico à vontade em expor a minha vida. O episódio me desperta para a criação de uma sociedade falsa, cria sensações e emocões para agradar. Criando um mundo irreal e falso. É difícil pensar num educador que não fale o que pensa. Não posso omitir o que penso.

Ao mesmo tempo em que as falas fazem referência às singularidades das redes sociais digitais como um "outro" mundo, assumem que o mundo é o mesmo, ou seja, estamos num mundo que integra múltiplos espaços, tempos, ideias, possibilidades. A fala do participante F "O episódio me desperta para a criação de uma sociedade falsa, cria sensações e emoções para agradar. Criando um mundo irreal e falso. E ao mesmo tempo "É difícil pensar num educador que não fale o que pensa. Não posso omitir o que penso" traz o paradoxo, a coexistência num mundo que não pode ser falso ou irreal.

Hoje, os suportes e tecnologias de rede são canais potencializadores de tipos de partilha de saberes ou que o Lévy (2014) chama de "prática partilhada". No campo da educação, a ideia de mediação partilhada foi desenvolvida por Bruno (2002) e adquire sentido semelhante:

A partilha não vem no sentido da permissividade, da inclusão do outro, visto que todos já estão no e são o processo em si. Tal processo é possível desde que existam interagentes que desejem ali estar. Partilhar é movimento de produção de devires, olhares, percepções, ser e estar os devires latentes nas emergências daquele encontro, daquela acontecência [...] não há uma única liderança, mas emergências. Isso faz com que o processo de mediação crie espaços para partilhas, no interior das quais todos sejam líderes em potencial, protagonistas das cenas e do cenário de aprendizagem (BRUNO et al, 2012, p. 10). 
O debate a partir deste episódio da série ainda nos permitiu compreender melhor o que Lévy (2014) abordou como conversação criativa (CC), em que o con-versar implica em voltar o fluxo discursivo para o outro, trocar fluxos, trocar com o outro, junto com outrem, por meio de movimentos de fluxos implícitos e explícitos nos espaços de relação social.

\section{Vivência 3: a violência na rede e na vida: adolescentes discutem o ciberbulliyng de "shut up and dance" \\ ("manda quem pode")}

A terceira atividade envolvendo processos formativos em diálogo com a série teve como disparador um convite ao GRUPAR para discutir os temas Bulliyng e Ciberbullying numa ONG em Juiz de Fora-MG, num espaço destinado a Medidas Socioeducativas, com adolescentes em situação de semi-liberdade ${ }^{8}$. Para trabalhar a temática, optou-se pela utilização fílmica, seguida de discussão. Portanto, o tema foi apresentado e debatido a partir do episódio Shut Up and Dance ("Manda quem pode" - Temporada 3, episódio 3). Neste dia, acompanhados de professores e agentes que atuam no polo, dialogamos com 17 adolescentes com idades que variam entre os 12 e os 17 anos.

A atividade foi previamente anunciada pelos integrantes do grupo de pesquisa que, à convite da pedagoga que atua na instituição, abordou a temática do Bullying e o Ciberbullying. Adotando uma perspectiva dialógica, o grupo de pesquisa optou por uma atividade que desencadeasse as vozes dos participantes, cocriando espaços de produção de narrativas, promovendo o debate. Diante do desafio que se apresenta nos tempos atuais e em articulação ao cenário vivenciado por aqueles jovens, a temática foi amplamente acolhida e apresentada para a discussão no encontro proposto.

\footnotetext{
8 O cumprimento de medidas socioeducativas de semiliberdade faz parte da política do Estado de Minas Gerais que segue o "Plano Mineiro de Desenvolvimento Integrado" (PMDI) 2007-2023 e fundamenta-se no Estatuto da Criança e do Adolescente (ECA) no tocante a aspectos pedagógicos e sociais. A solução alternativa para o restabelecimento de relações com a comunidade é a de dar ao adolescente oportunidade de se reintegrar à sociedade no período do cumprimento de seu ato infracional.
} 
Segundo os dados da pesquisa TIC Kids Online Brasil 2015 sobre o uso da internet, $20 \%$ dos usuários com idades entre 9 e 17 declaram ter sofrido ofensas durante o ano que antecedeu a pesquisa. Além disso, 40\% dos usuários da mesma faixa etária afirmam terem testemunhado discriminação na Internet. A proporção aumenta, para $52 \%$ entre os adolescentes de 15 a 17 anos. Outro dado importante, TIC Kids Online Brasil 2015, sobre esse tema é o da vulnerabilidade on-line. Muitos adolescentes confirmaram que, apesar da facilidade de domínio do manuseio os dispositivos, nem sempre estão conscientes dos riscos associados à navegação na internet. Pelos números levantados, quanto mais velha a criança ou adolescente, ocorre a possibilidade de exposição na rede de seus dados pessoais. De acordo com dados da mesma pesquisa, 25\% dos adolescentes entre 15 e 17 anos usuários de Internet afirmam estar arrependidos por terem acessado algum conteúdo.

Em se tratando de um grupo de adolescentes que cumprem medida socioeducativa, que têm suas vivências constituídas em situações de violência e risco social, trazer suas vozes para o diálogo sobre o Bullying e do Ciberbullying seria uma experiência rica e interessante. É importante salientar que a escuta desses adolescentes é fundamental para nós pesquisadores que buscamos em nossas investigações, compreender a vida não apartada da linguagem humana, e que o conhecimento produzido nos espaços de formação sejam plenos de enunciados que possam debater temas que perpassam os sujeitos, que ao se pronunciarem, trazem sua visão de mundo nas suas falas impregnadas de sentidos.

Na compreensão responsiva ativa (BAKHTIN, 1997), o enunciado se constitui como elo de uma cadeia de enunciados, tendo em conta o fenômeno real e concreto da comunicação verbal e a existência do outro. Ao traçar considerações sobre os gêneros do discurso, discutindo criticamente as abstrações do campo da linguística para tratar do enunciado como unidade da comunicação verbal, Bakhtin (1997, p. 293) nos esclarece o quanto "a fala, só existe, na realidade, na forma concreta dos enunciados de um indivíduo: do sujeito de um discurso-fala".

O episódio é protagonizado pelo personagem Kenny, um adolescente educado e gentil que trabalha em uma lanchonete. Fora do horário de trabalho, no espaço de seu quarto, ele se conecta e, anonimamente, experimenta prazeres sexuais on-line. Numa ocasião que sua irmã havia utilizado seu notebook, Kenny se deparou com um malware 
que ela havia instalado involuntariamente ao tentar baixar um arquivo de filme. O jovem, demonstrando habilidade com o computador, faz o reparo do software invasor e, aparentemente restabelece o funcionamento de sua máquina. A partir desse momento o pesadelo é que começa se desenrolar numa angustiante sucessão de fatos de Shut Up and Dance ("Manda quem pode"). Um anônimo invade seu notebook com mensagens e começa a chantageá-lo com a ameaça de divulgar, na lista de amigos do adolescente, imagens dele se masturbando diante do computador, captada pelo criminoso virtual. A partir daí Kenny vive um alucinante de tortuoso drama, sendo obrigado a realizar uma sucessão de tarefas ordenadas pelo chantageador. Numa delas se depara com Hector, um pai de família que também se tornou refém do invasor, também ameaçado e impelido a cumprir ações atrozes que envolvem roubo e violência. O que marca a narrativa desse episódio angustiante e estarrecedor é a sensação de total fragilidade e controle das personagens por um invasor de sua privacidade. Essa ameaça onipresente não inclui somente os dois, mas outras pessoas com as quais vão se cruzar na trama, também vítimas do sádico vilão, que age com requintes de crueldade no poder que os assola e os impele ao mal.

Esse episódio, de chantagem virtual e violência se mostrou uma excelente escolha para a atividade desenvolvida com os adolescentes em semiliberdade do encontro proposto, e que desconheciam a série. Sem maiores apresentações sobre o tema do bullying ou do ciberbullying, a produção audiovisual apresentada aos jovens participantes, além de atrair bastante atenção enquanto fruição da obra, proporcionou diferentes comentários ao final da exibição. Ainda que o episódio mostrasse um adolescente britânico de uma outra realidade cultural e social, a situação de angústia e opressão vivida na rede, de acordo com os comentários que se fizeram, tiveram da parte dos jovens semiinternos dessa instituição de reabilitação social, a marca da presença das tecnologias e do quanto podemos estar expostos à violência. Assim manifestaram que, seja nas provocações pessoais nos espaços de convívio diário, assim no ambiente de rede, o bullying é uma realidade a qual enfrentam e se mostraram dispostos a debater.

Assistir ao episódio de Black Mirror desencadeou uma série de falas desses adolescentes, explicitando-se, aqueles que expuseram, o quanto os incomodam serem importunados no próprio ambiente da instituição em que cumprem pena em semiliberdade. O meio digital instiga às práticas violentas? Será que os jovens estão preparados para lidar com situações como as vistas no episódio de Black Mirror em 
questão? $\mathrm{O}$ anonimato tem estimulado o ciberbullying e outras práticas que tornam os jovens reféns de ameaças? Como atuar nesse contexto tecnológico em que os perigos podem ser iminentes?

Algumas dessas questões foram debatidas e os adolescentes, tirando alguns posicionamentos, demonstraram a importância dos cuidados e atenção ao transitarem e manterem relações nas redes de contato, dos perigos de se envolverem em situações de provocação e também de exposições deturpadas de pessoas, expressas nos memes de internet, que circulam nas redes sociais e outros aplicativos de relacionamento.

Um ponto curioso notado no grupo foi a dificuldade em desvincular a ficção do que ocorre na "vida real". Os jovens abordaram o episódio como se fosse verdade e queriam saber o que aconteceu depois. Ao afirmarmos que não há continuidade daquela história, mostraram-se frustrados e inconformados. O contexto daqueles jovens está cercado de "realidades", de histórias com começo, meio e fim, claramente apresentados. Pensar numa narrativa em aberto provoca nestes "meninos" sensações de estranhamento, como se as histórias não pudessem ser reinventadas, reescritas, redimensionadas.

Um jovem, mais extrovertido e falante, foi um dos primeiros a se manifestar dizendo que para ele, qualquer ameaça e agressão deve ter o revide na mesma medida e que ele considera que devemos agir assim, seja na realidade concreta ou on-line.

Já outro adolescente, bastante articulado e interessado na discussão, se posicionou contrário à opinião do colega, dizendo que essa postura só amplificaria a violência, conforme foi visto na série, onde o personagem de Kenny ingressou num ciclo de violência que se intensificava a cada ação praticada. Sua fala foi corroborada com o comentário de outros participantes da atividade, que concordaram que a violência estimula outros atos de agressão e que se deve buscar outras alternativas para situações de bullying e provocações, seja on-line ou off-line.

Sobre a cibercultura emergente, um dado importante de um mergulho na vida dos adolescentes revela mais do que uma apropriação técnica do meio. Boyd (2015) faz um movimento que se distancia de tratar as novas gerações adaptadas num cenário sem conflitos em visões que expressam um determinismo tecnológico, presente em visões utópicas e distópicas sobre as tecnologias. Tendo em conta que as culturas juvenis que desafiam a compreensão dos adultos, como identidade, privacidade, dependência das 
tecnologias, perigos on-line, bullying e desigualdade, a autora ressalta que os media sociais funcionam para muitos dos adolescentes, com vida restringida fora desses espaços, como uma plataforma que contribui nos seus processos de maturação. Nesses espaços on-line ocorre a permanência e amplificação de conflitos, segregações e preconceitos. Vale destacar dessas considerações o questionamento sobre o tão difundido rótulo de que os jovens de hoje são nativos digitais. Contrariamente aos posicionamentos simplistas de que as novas gerações, nascidas em um mundo com internet e povoado pelas novas tecnologias, estão automaticamente aptas no domínio desse ambiente informacional, a autora problematiza o tema.

Para Boyd (2015), a noção de nativo digital esconde a desigualdade das competências tecnológicas e do real conhecimento dos jovens na era digital. Nesse sentido, o argumento é de que a literacia midiática é fundamental nos espaços de educação, proporcionando uma formação crítica dos jovens sobre os media. Muitas vezes eles estão aprendendo a lidar nesses sistemas por sua própria iniciativa, tanto adquirindo conhecimento especializado, como também lidando com dificuldades, limitações e restrições de acesso no domínio desse ambiente.

Corroborando nesse sentido, Barrère (2011) afirma que a revolução digital não produziu novos adolescentes, somente atuou para radicalizar e multiplicar práticas já existentes na cultura. A muito difundida dessa geração como digital natives é uma superestimação daquelas que a precederam, que estariam sendo ultrapassadas ou mesmo se sentem incomodadas pelas novas tecnologias levando em conta a competência técnica. O que ocorre é um alargamento da autonomia dos adolescentes sustentados pelos suportes, incluindo a subtração do controle parental no acesso e utilização das mídias. A autora acrescenta que ocorre um adensamento à chamada cultura do quarto com a possibilidade de um conjunto de suportes acessíveis de diferentes mídias de imagem, texto, som e formas de diversão. Apesar de que nem a escola e nem a família renunciaram seu acompanhamento, ainda que não sejam considerados superados em seus papéis, elas são permissivas e complacentes com essas posturas dos adolescentes. As instituições não renunciam, mas a elas são impostos novos desafios.

Assim como o debate entre os adolescentes que cumprem medida socioeducativa, onde suas vozes se manifestaram para se posicionar sobre o quanto a violência está presente nos ambientes digitais e no convívio, as reflexões teóricas também apontam que 
existe uma vulnerabilidade das novas gerações na cibercultura emergente. Ainda que haja um domínio das ferramentas e a facilidade ampliada do acesso às tecnologias nas mais diferentes formas de atuação, Shut Up and Dance ("Manda quem pode") apresenta um cenário que se aproxima das últimas consequências de uma situação de Ciberbulliyng, nos alertando para o quanto os adolescentes devem ser convidados ao debate sobre temas que lhes são muito próximos, refletindo sobre suas opiniões, práticas e atitudes nesse contexto.

\section{Considerações finais}

As três vivências (trans)formativas produziram múltiplos sentidos para as ideias chave propostas para experiência de ensino-pesquisa ora partilhada, a saber as ideias e atos de utopia, distopia e retrotopia.

No episódio Nosedive, experienciado em dois momentos distintos, os pontos de convergência sinalizaram que os apelos de uma sociedade que tem sua utopia muito calcada em likes, projetando um futuro em que as propostas de bom conviver precisam ser testados e avaliados pelo outro, de forma indiscriminada e aparente, merece cuidados intensos. O culto à vaidade, ao sucesso e ao consumo pode trazer desdobramentos indesejáveis como a intolerância, discriminação, discursos e práticas de violência que podem fugir ao controle. As a/enunciações de uma cibercultura tratada por Lévy (1999) e de uma sociedade em redes como sistema aberto abordada por Castells (2007) criam cenários que emergem no episódio como utópicos e distópicos.

Em análise convergente a tais movimentos, o episódio White Bear infere as múltiplas possibilidades de se creditar moral e ética no mundo contemporâneo, alertado por La Taille (2016), resgatando mais uma vez cenários de violência. A fusão de preceitos de uma determinada moral, se sobrepõe a princípios éticos universais da coexistência humana. Os dispositivos tecnológicos digitais assumem papel mediador ora para esconder a face nua e crua dos "algozes justiceiros", tal qual no episódio anterior, ora para registrar e revelar as ideias defendidas por uma moral que é singular, mas jamais unânime.

Por fim, o episódio Shut Up and Dance, coroando as discussões e interpretações trazidas no presente texto, reflete o quanto a violação da intimidade aufere processos hibridatórios de medo, controle e conflitos, promovendo mais uma vez ideias e atos de 
violência, sempre em prol da aceitação social, o que se liga com o episódio inicialmente trabalhado, Nosedive.

A distopia, como o outro lado da utopia, mas não o seu contrário, cria uma trama espiralada de ocorrências em congruência com a ideia de retrotopia. Os episódios experiênciados fomentaram a produção de redes que produzem movimentos não excludentes utópicos-distópicos-retrotópicos — não sempre nesta ordem —, que sinalizam os flashs de culturas que convivem e se fazem nos três movimentos como possibilidade de composição e não de exclusão.

Para além de refletir nossa existência tão plural, estas vivências contribuem para enriquecer, ampliar, redimensionar, tensionar e transformar as ideias e o debate sobre tecnologias digitais e suas potencialidades, ratificando que os ambientes de formação, no campo da educação, podem se constituir como espaços de trans-formação, potentes para exercer a criticidade necessária para compreender os impactos da cibercultura nesse mundo bodierno.

\section{Referências}

ÁLVARO MÉNDEZ, J. M. Avaliar para conbecer examinar para excluir. Porto Alegre: Artmed, 2002.

BAKHTIN, M. Estética da Criação Verbal. São Paulo: Martins Fontes, 1997.

BARRÈRE, A. L'éducation Buissonnière. Quand les adolescents se forment par eux-mêmes. Paris: Armand Colin, 2011.

BAUMAN, Z. Bauman: assim chegamos à Retrotopia. Diálogo com a Spyked Review. Trad. Inês Castilho. In: Outras Palavras, 2017. Disponível em: < https://outraspalavras.net/posts/baumanassim-chegamos-a-retrotopia-2/>. Acesso em: 10 set. 2018.

BOYD, D. É complicado. A vida social dos adolescentes em rede. Lisboa: Relógio d'Água Editores, 2015.

BRUNO, A. R. et al. Coaprendizagem em rede na formação docente: plasticidade, colaboração e rizomas. In: OKADA, A. (Ed.). Open Educational Resources and Social Networks: Co-Learning and Professional Development. London: Scholio Educational Research \& Publishing, 2012. Disponível pelo endereço: <http://oer.kmi.open.ac.uk/wpcontent/uploads/cap14_grupar.pdf>. Acesso em: out. 2018.

BRUNO, A. R. A Linguagem Emocional em Ambientes Telemáticos: tecendo a razão e a emoção na formação de educadores. Dissertação (Mestrado - Programa de Pós-Graduação em Educação: Currículo). Pontifícia Universidade Católica de São Paulo, São Paulo: 2002. 
CASTELLS, M. A sociedade em rede. Trad. Roneide. São Paulo: Paz e Terra, 2007.

CETIC.BR. Centro Regional de Estudos para o Desenvolvimento da Sociedade da Informação. Kids online Brasil 2016. São Paulo, 2017. Disponível em: <tic.br/media/docs/publicacoes/2/TIC_KIDS_ONLINE_2016_LivroEletronico.pdf>. Acesso em: 18/04/2019.

CLANDININ, D. J.; CONNELLY, F. M. Narrative Inquiry: experience and story in qualitative research. Trad. Narrative Inquiry Group and Teacher Education ILEEI/UFU. Uberlândia: EDUFU, 2011. 250 p.

COUTO, J. L. P. Mundos fabulados. In: XI Encontro Regional da ABCiber - UFJF, Juiz de ForaMG, 2018.

DEBORD, G. A sociedade do espetáculo. E-book Brasil. 2003. Disponível pelo endereço: <https://www.marxists.org/portugues/debord/1967/11/sociedade.pdf>. Acesso em: 01 ago. 2018.

DELEUZE, G.; GUATTARI, F. Mil Platôs: capitalismo e esquizofrenia. Trad. Aurélio G. Neto e Célia Pinto Costa. São Paulo: Ed. 34, 1997.

FREIRE, P. Educação e Mudança. Rio de Janeiro: Paz e terra, 2006 a.

FREIRE, P. Pedagogia da Autonomia: Saberes necessários à prática educativa. 34. ed. Rio de Janeiro: Paz e Terra, 2006b.

GALLO, S. Deleuze e a Educaşão. São Paulo: Vozes, 2008.

JACOBY, R. Imagem imperfeita: pensamento utópico para uma época antiutópica. Rio de Janeiro: Civilização Brasileira, 2007.

LA TAILLE, Y. Moral e Ética no Mundo Contemporâneo. Revista USP, n. 110, p. 29-42, jul./set. 2016.

LEMOS, A. Isso (não) é muito "Black Mirror": passado, presente e futuro das tecnologias de comunicação e informação. Salvador: EDUFBA, 2018.

LÉVY, P. The Semantic Sphere 1. Computation, Cognition and Information Economy. Canadá: Wiley Iste, 2014.

LÉVY, P. Cibercultura. Trad. COSTA, C. I. São Paulo: Editora, 1999.

RECEBIDO: 30/07/2019

APROVADO: 21/08/2019
RECEIVED: 07/30/2019

APPROVED: 08/21/2019
RECIBIDO: 30/07/2019

APROBADO: 21/08/2019 